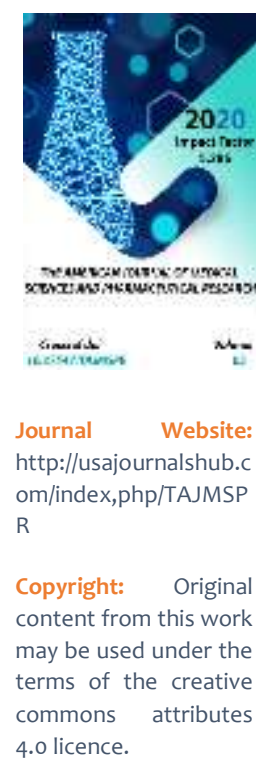

\title{
Performance And Causes Of Skin Leishmaniosis In Surkhandarya Region
}

Jamshed Jafarovich Jalilov

Lecturer, Basics Of Valeology, Termez State University, Uzbekistan

\section{ABSTRACT}

The article is scientifically based on the prevalence and causes of cutaneous leishmaniasis in the southern region of Uzbekistan, Surkhandarya region.

\section{KEYWORDS}

Zoonosis, sand mouse, Leishmania major, Leishmania turanica, Ph.papatasi, zoonosis skin leishmaniasis, visceral leishmaniasis.

\section{INTRODUCTION}

Leishmaniasis is a tropical disease that is endemic in 98 countries today. Leishmaniasis is a transmissible protozoal disease of humans and animals, the causative agent of which is leishmaniasis, which is transmitted by the bite of carrier scorpion flies.

According to the World Health Organization, 350 million people live in areas at risk of leishmaniasis. 600,000 to $1 \mathrm{ml}$ per year. Patients with cutaneous leishmaniasis are registered. In addition, 50,000 deaths from visceral leishmaniasis are reported each year. The incidence of cutaneous leishmaniasis has been increasing in recent years [10].

Visceral and cutaneous urban leishmaniasis are almost extinct in Central Asian countries, but zoonotic cutaneous leishmaniasis continues to occupy a significant place among infectious diseases. The main outbreaks are in Uzbekistan and Turkmenistan, as well as in some parts of Kazakhstan $[3,4]$.

Visceral zoonosis and cutaneous anthroponosis and zoonotic leishmaniasis are widespread in the Republic of Uzbekistan, of 
which there are about 40 natural foci of cutaneous leishmaniasis. Epidemiologically, the most active natural foci of zoonotic skin leishmaniasis in Uzbekistan are Bukhara, Kashkadarya, Navoi, Surkhandarya regions and the Republic of Karakalpakstan [1], and endemic foci are mainly in rural and urban areas in the desert. Summer seasonal damage in these areas is associated with the period of activity of scorpions. The natural source of the zoonotic skin leishmaniasis pathogen in Uzbekistan is the large sand mouse and the red-tailed sand mouse, and the carrier is the iskabtopar mosquito (Ph.papatasi) [2].

The problem of cutaneous leishmaniasis in the country has been studied mainly by dermatovenerologists and epidemiologists: A.Sh. Vaisov substantiated the procedure for clinical and experimental evaluation of the effectiveness of collagen monomycin complex in acute necrotic cutaneous leishmaniasis (A.Sh. Vaisov, 1978, 1989); improved study of clinical, microbiological and immunological indicators of cutaneous leishmaniasis (Z.M.Abidova et al., 2014, 2015, 2016, 2017); immunogenetic features of cutaneous leishmaniasis have been studied (I.R. Rakhimov, 2017), however, the prevalence and clinical features of cutaneous leishmaniasis as well as the pathogenetic treatment regimen as well. measures to reduce the incidence of cutaneous leishmaniasis, to eliminate its natural foci, have not been fully developed, i.e. to date, the prevalence of leishmaniasis and treatment methods have not been fully resolved. Also, the analysis of the available literature shows that in Uzbekistan, including in Surkhandarya region, there is a lack of scientific research on the problem of zoonotic skin leishmaniasis. Therefore, conducting research on this topic is of great scientific and importance and determines the relevance of the topic.

\section{THE PURPOSE OF THE STUDY}

Scientific substantiation of the prevalence and causes of cutaneous leishmaniasis in Surkhandarya region.

\section{THE RESULTS OBTAINED AND THEIR ANALYSIS}

In the zoonotic skin leishmaniasis of the population, each outbreak has its own characteristics, depending on the location of habitats and natural foci, the degree of migration and contact of the population with them, the level of immunity of the population. Also, where the impact of anthropogenic factors on the environment is significant, as a rule, there is an epidemic outbreak of zoonotic skin leishmaniasis.

In Surkhandarya region, the incidence of cutaneous leishmaniasis is observed in the city of Termez, the regional center, and in desert areas and oases with surface or groundwater flows. In particular, the analysis of the prevalence of zoonotic skin leishmaniasis in the city of Termez and Termez district revealed the spread of 2 types of this pathogen (Leishmania major and L.turanica) [6].

Infection with leishmaniasis occurs in MayAugust, the onset of clinical signs of the disease occurs in August-September.

Zoonotic skin Typical changes occur in human skin after the bite of a scabies infected with leishmaniasis. The number of wounds can range from one to ten or more, depending on the number of bitten scabies affected. Because the disease is associated with scabies, leishmaniasis is usually located on the exposed surfaces of the body, such as the face, neck, 
eyes, and legs. However, in the hot climate of Termez, people wear light clothes and do not cover their wounds when they sleep, so wounds can occur in other areas of the body.

The latent period of zoonotic skin leishmaniasis lasts from 1 to 4 weeks in most cases and from 1.5 to 2 months in rare cases [5].

The stage of zoonotic skin leishmaniasis infiltrate lasts 2-3 weeks. A raspberry-colored red spot appears at the site of the bite, which turns into a nodule, is a reddish furunculosis infiltrate, $20-30 \mathrm{~mm}$ in diameter. The infiltrate rises to the surface of the skin, becomes hyperemic, the surrounding tissue is swollen. Patients complain of itching in this area and pain when pressed a little, but do not seek medical attention during this period. Tissue necrosis begins in the central part of the infiltrate and the disease progresses to the next stage. The injury phase lasts for 2-3 months. In place of the infiltrate, a deep wound gradually appears, the edges of the wound are uneven, "like a dig", 1-5 cm in diameter. Infiltration and dimmed hyperemia are observed in the periphery of the wound. In rare cases, a large number of fertilization bumps appear around the wound, which are injured and scarred. Boundaries outside the border are serous-purulent, usually easily covered with a movable gray or brown crust. The bottom of the wound is covered with a yellowish - gray necrotic substance. Usually, the wound is painful during this period. The scarring stage is when the bottom of the wound is gradually cleared of necrotic tissue and covered with granulation, which gives the bottom of the wound the appearance of granules (a symptom of "fish caviar" or "cut pomegranate"). Sometimes vegetation or even warts form in the center of the wound. During this period, the separation of the wound from the wound first decreases, then stops. In turn, a scar is formed, starting from the center and leaving a wound "ring" at the edges. 4-6 months after the onset of the disease, a "seal" scar is formed, the nature of which depends on the severity of the disease $[5,7]$.

Usually, stable immunity is formed after the transmitted disease. Recurrence of the disease is observed in $2-10 \%$ of patients. With the scarring of leishmaniasis, immunity is strengthened. However, it is known from the literature that in some patients the disease may recur even several years after the end of the disease [8].

Although current measures against cutaneous leishmaniasis are to some extent effective, they are not adequate. The fact that the disease is registered in a stable state among the population of the country from year to year confirms that in recent years it has increased slightly.

Epidemiological analysis methods were used to study the epidemiological features of cutaneous leishmaniasis.

The average incidence of cutaneous leishmaniasis in Surkhandarya region is 5 times higher than the national average. In Surkhandarya region, the incidence of skin leishmaniasis in the first 2015 of the analysis was $2.9 \%$ per 100 thousand population, and by 2019 it was $6.1 \%$.

That indicates in our monthly analysis of patients with cutaneous leishmaniasis in 20152019, the incidence was $17 \%$ in August, $57 \%$ in September-October, and $26 \%$ in NovemberDecember (picture - 1). 
The results of a study on the prevalence of skin leishmaniasis among men and women in Surkhandarya region in 2015-2019 show that $56 \%$ of men and $44 \%$ of women were infected with cutaneous leishmaniasis between 2015 and 2017, and in 2017-2019 there were more cases than women (picture - 2).
In the analysis of the incidence of cutaneous leishmaniasis in Surkhandarya region in 20152019 by youth, $0-1$ year olds accounted for $2.9 \%$, $1-2$ year olds for $6.0 \%, 3-4$ year olds for $7.5 \%, 5-10$ year olds $5.9 \%$, $11-15$ year olds $14.6 \%, 16-20$ year olds $13.4 \%, 21-30$ year olds $17.6 \%$, 31-40 year olds $12.1 \%$, over 41 years old $20 \%$ (table -1 ).

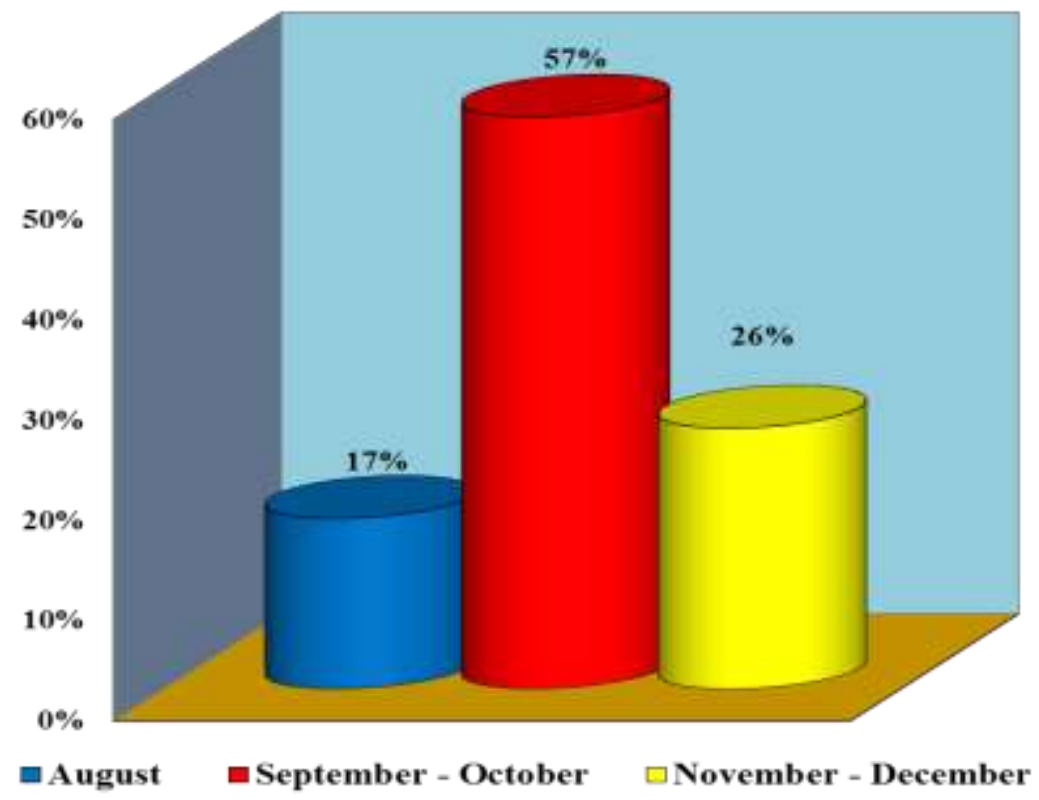

1-

Monthly analysis of patients with cutaneous leishmaniasis

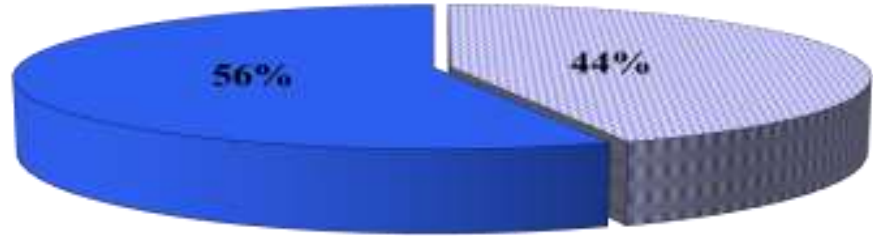

ロWomen

घ Men

2-picture. The prevalence of zoonotic skin leishmaniasis by sex 


\section{Table - 1}

\section{Age analysis of skin leishmaniasis (Surkhandarya region) 2013-2019}

\begin{tabular}{|c|c|c|c|c|c|c|c|c|c|c|c|}
\hline \multirow{2}{*}{ № } & \multirow{2}{*}{ Years } & \multicolumn{8}{|c|}{ Ages } & \multirow{2}{*}{ Above age 41} & \multirow{2}{*}{ Total: } \\
\hline & & $0-1$ & $1-2$ & $3-4$ & $5-10$ & $11-15$ & $16-20$ & $21-30$ & $31-40$ & & \\
\hline 1 & 2015 & 2 & 5 & 10 & 9 & 23 & 22 & 34 & 15 & 29 & 149 \\
\hline 2 & 2016 & 5 & 17 & 14 & 13 & 33 & 39 & 43 & 28 & 46 & 238 \\
\hline 3 & 2017 & 11 & 15 & 22 & 17 & 37 & 33 & 49 & 32 & 54 & 270 \\
\hline 4 & 2018 & 7 & 13 & 17 & 13 & 36 & 27 & 40 & 30 & 49 & 232 \\
\hline 5 & 2019 & 8 & 19 & 23 & 16 & 39 & 33 & 36 & 33 & 51 & 258 \\
\hline \multicolumn{2}{|c|}{ Total: } & 33 & 69 & 86 & 68 & 168 & 154 & 202 & 138 & 229 & 1147 \\
\hline
\end{tabular}

Thus, the above data show that in Surkhandarya region, skin leishmaniasis is more common in the population of all ages, and is more common among the elderly, ie able-bodied people. It is known that reliable statistics on any disease serve as the main source of information and form the basis for scientific research. Unfortunately, there is currently uncertainty in the number of people with cutaneous leishmaniasis due to the fact that people with cutaneous leishmaniasis do not go to medical facilities but go to local doctors for treatment at home.

The natural source of the disease in the border areas of the Amu Darya River, which flows from the south of Surkhandarya region and along its banks, consisting of tugai forests and thick forests, is the prevalence of rodents, and the increase in the number of scorpionfish causes leishmaniasis in many rural areas. The main reasons for the spread of the disease in the city are rodents, the basements of apartment buildings are filled with water from sewage, and the number of carriers of the disease is growing.

\section{CONCLUSION}

This means that despite the fact that in some countries of the world today, viral and cutaneous leishmaniasis are almost eliminated, the problem of zoonotic cutaneous leishmaniasis remains relevant for modern parasitology. Although Uzbekistan has made significant progress in combating this parasitic infection in recent years, Surkhandarya region has natural foci of the disease. The endemicity of cutaneous leishmaniasis is related to the living conditions of this disease carrier. These features explain the high prevalence of this disease in Uzbekistan, as well as in the southern regions, as well as in tropical and subtropical countries.

\section{REFERENCES}


1. Abdnev T.A., Suvonkulov U.T., Kovalenko D.A., Abdiev F.T., Arziev Kh.Yu. Prevalence of helminthiasis in Uzbekistan. // Biology wa tibbiet muammolari. Samarkand - 2014 No. 3 - P. 16-17.

2. Alyavi S.F. Clinical and experimental substantiation of the use of "Leshmicin" ointment in case of zoonotic cutaneous leishmaniasis (clinical and experimental study). - Dis. Cand. honey. sciences. Tashkent, 2000 .-- 155 p.

3. Baratova M.R., Shodiev U.Kh. Clinic of the modern urban type of skin leishmaniasis. // Materials of the scientific-practical conference "Actual problems of dermatology and venereology". Tashkent, May 12-13, 2006 p. 71-72,

4. Bronshtein A.M., Malyshev N.A., Davydova I.V. et al / Observations of zoonotic cutaneous leishmaniasis in Moscow tourists visiting Tunisia and their successful therapy with ketoconazole // Russian Journal of Skin and Venereal Diseases. 2005. -N6. -FROM. 30-33.

5. Sergiev V.P., Ponirovsky E.N. WHO Regional Meeting: "Developing a Strategic Plan for Leishmaniasis Control": Tbilisi, Georgia, April 16-18, 2013 // Medical Parasitology and Parasitic Diseases. - $M$ ,2013.-N4.-S. 59-61.

6. Mustafaev Kh.M. Modern features of epidemiology and optimization of epidemiological surveillance measures in foci of zoonotic cutaneous leishmaniasis in the developed territories (on the example of the Republic of Uzbekistan). - Dis. Cand. honey. sciences. - Moscow, 1991 -- 189 p.

7. Narzikulov R. M. Abdullaev D. M. Experience of using glucantim in cutaneous leishmaniasis: Abstracts of scientific works of the International scientific and practical conference "Actual problems of dermatovenerology and aesthetic medicine (Tashkent, November 20-21, 2015) I/ Dermatovenereology and aesthetic medicine - Tashkent, 2015 .-- Volume 27 N3 -- P. 217.

8. Damania B., Dittmer D.P. What lies within: coinfections and immunity // Cell Host Microbe. - 2014 - Vol. 16 - №2. - P. 145-147.

9. Sanitary epidemiological Surkhandarya region peace center report for 2016-2019.

10. Weekly epidemiological record of WHO // №40. 2018. 93, 521-540.

11. jamshedjalilov93@gmail.com 